\title{
Optimizing dosing frequencies for bisphosphonates in the management of postmenopausal osteoporosis: patient considerations
}

John Sunyecz

MenopauseRx, Inc., Hopwood, PA, USA
Correspondence: John Sunyecz President, MenopauseRx, Inc., Laurel Highlands Ob/Gyn, P.C., I 42 National Pike Road, Hopwood, PA 15445, USA Tel + I 7243223665

Fax + I 7244388856

Email sunyecz@menopauserx.com

\begin{abstract}
Postmenopausal osteoporosis is common and underrecognized among elderly women. Osteoporotic fractures cause disability and disfigurement and threaten patients' mobility, independence, and survival. Care for incident fractures in this age group must go beyond orthopedic repair, to assessment and treatment of the underlying bone fragility. Fracture risk can be reduced by vitamin $\mathrm{D}$ and calcium supplementation along with antiresorptive drug treatment. First-line osteoporosis pharmacotherapy employs nitrogen-containing bisphosphonates. The inconvenience of daily oral treatment has motivated development of weekly, monthly, and intermittent oral regimens, as well as quarterly and yearly intravenous (iv) regimens. Ibandronate is the first bisphosphonate to have shown direct anti-fracture efficacy with a non-daily regimen; it was approved for once-monthly oral dosing in 2005 and for quarterly iv dosing in 2006. Intermittent oral risedronate and yearly iv zoledronic acid were approved in 2007. Newly available regimens with extended dosing intervals reduce the inconvenience of bisphosphonate therapy and provide patients with a range of options from which to select a maximally sustainable course of treatment. This review discusses the development, efficacy, safety, and tolerability of extended-interval bisphosphonate regimens and examines their potential to improve patient acceptance and long-term success of osteoporosis treatment.
\end{abstract}

Keywords: ibandronate, alendronate, risedronate, zoledronic acid, adherence, persistence

\section{Background}

Osteoporosis - a progressive loss of bone strength and quality that multiplies fracture risk - is a common and underrecognized hazard to postmenopausal women. Its prevalence among US women ranges from $26 \%$ at age 65 years and older to over $50 \%$ at age 85 years and older (US Department of Health and Human Services 2004), reflecting an altered balance of bone turnover that begins immediately upon menopause and increases steadily with age (Garnero et al 1996b). Fortunately, osteoporosis is eminently preventable and treatable. Lifelong attention to nutrition and exercise, bone density monitoring after menopause, and appropriate treatment of diagnosed osteoporosis can reduce the burden of disability, cost, and mortality.

Bone densitometry by dual-energy X-ray absorptiometry (DXA), which measures bone mineral density (BMD), is the canonical method for diagnosing osteoporosis (Briot and Roux 2005). The relationship between low BMD and fracture is stronger than the relationship between cholesterol and heart attacks (US Department of Health and Human Services 2004). Judicious BMD testing should be considered in at-risk postmenopausal women, in younger women with multiple risk factors, and in all patients who present with fragility fractures or take medications that can reduce BMD (US Department of Health and Human Services 2004). At a minimum, BMD screening of all men and women should be considered at 65 years of age. 
The World Health Organization (WHO) defines osteoporosis as a BMD T-score of $\geq 2.5$ standard deviations below the gender-specific young adult mean, as measured by DXA (World Health Organization 1994). However, total fracture risk reflects both BMD-dependent and BMD-independent risk factors (Kanis et al 2007). The 2008 National Osteoporosis Foundation practice guidelines (National Osteoporosis Foundation 2008) (Table 1) utilize FRAX ${ }^{\mathrm{TM}}$, the new WHO absolute fracture risk algorithm (Kanis 2008), which takes into account BMD, age, smoking, alcohol intake, personal or parental history of fracture, body mass index, corticosteroid use, and rheumatoid arthritis to predict individual patients' 10 -year probability of sustaining osteoporotic fractures.

Osteoporotic fractures, with an estimated annual incidence of 2 million among US citizens aged 50 years or older (Burge et al 2007), have severe physical, economic, and psychosocial consequences. Direct physical consequences include temporary or permanent disability and disfigurement. If fracture sufferers become bedfast, indirect consequences such as decubitus ulcers, pneumonia, and urinary tract infections may result (US Department of Health and Human Services 2004). Mortality risk increases 2.8- to 4-fold during the first 3 months after a hip fracture (US Department of Health and Human Services 2004). In the US, 500,000 hospitalizations, 800,000 emergency room visits, and 180,000 nursing home placements yearly are attributable to osteoporotic fractures (US Department of Health and Human Services 2004), requiring annual direct care expenditures estimated at US $\$ 16.9$ billion and total costs exceeding US\$19 billion (2005 dollars) (Burge et al 2007). A 2007 case-control study reported incremental costs of US\$4,007 per Medicaid beneficiary or US\$5,370 per Medicare beneficiary during the first post-fracture year (Rousculp et al 2007).

A particularly distressing cost of osteoporosis to elderly patients and their families is potential loss of independence. Fracture sufferers often lose more mobility through fear than they lose to the direct effects of injury. This effect can synergize with the direct effects of fractures on mobility and morbidity to cause self-perpetuating inactivity, social isolation, and functional dependence, often culminating in institutionalization (US Department of Health and Human Services 2004).

Calcium and vitamin D supplementation are essential in the prevention and therapy of osteoporosis and have been used in all of the major trials of osteoporosis drugs (Sunyecz and Weisman 2005). The US Institute of Medicine's estimated adequate intakes for adults aged $\geq 50$ years are $1200 \mathrm{~g}$ calcium (with $\geq 700 \mathrm{mg}$ preferably derived from diet) and 800-1000 units vitamin D (Standing Committee on the Scientific Evaluation of Dietary Reference Intakes 1997). Calcium supplementation (1000 mg/day) prevents BMD loss and may reduce vertebral fractures in postmenopausal women, as shown in a meta-analysis by the Agency for Health Research and Quality (MacLean et al 2008). Vitamin D (700-800 international units/day) with or without calcium reduced hip and non-vertebral fractures versus placebo in another meta-analysis (Bischoff-Ferrari et al 2005).

Table I Diagnostic categories of BMD and appropriate clinical responses (World Health Organization 1994; Healy 1998; Hodgson et al 200I; Kanis 2008)

\begin{tabular}{|c|c|c|}
\hline Classification & T-score & Clinical response \\
\hline Normal & Exceeding -I & $\begin{array}{l}\text { - Reassure } \\
\text { - Encourage adequate calcium and vitamin D intake and } \\
\text { weight-bearing exercise }\end{array}$ \\
\hline Osteopenia & $<-\mid$ to $>-2.5$ & $\begin{array}{l}\text { - Maintain nutrition and exercise } \\
\text { smoks risk factors (personal or family history of fracture, } \\
\text { corticosteroid use, rheumatoid arthritis) } \\
\text { - Consider bisphosphonate treatment if } 10 \text {-year hip fracture } \\
\text { probability is } \geq 3 \% \text { or probability of any major osteoporotic } \\
\text { fracture is } \geq 20 \% \text { by regionally appropriate WHO model at } \\
\mathrm{http}: / / \text { www.shef.ac.uk/FRAX/index.htm }\end{array}$ \\
\hline Osteoporosis & -2.5 or less & $\begin{array}{l}\text { - Maintain nutrition and exercise } \\
\text { - Assess and reduce risk of falls } \\
\text { - Institute bisphosphonate therapy }\end{array}$ \\
\hline Severe osteoporosis & -2.5 or less and fragility fracture & $\begin{array}{l}\text { - Maintain nutrition and supervised/adapted exercise (avoiding } \\
\text { spinal twists, forward bends, and high-impact activities) } \\
\text { - Assess and reduce risk of falls } \\
\text { - Continue bisphosphonate therapy }\end{array}$ \\
\hline
\end{tabular}


In addition to lifelong preventive nutrition and weight-bearing exercise, antiresorptive treatment with nitrogen-containing bisphosphonates has become standard first-line therapy for postmenopausal osteoporosis. Timely diagnosis and effective treatment of osteoporosis can reduce the incidence of fractures and their multifaceted individual and societal costs.

\section{Objective}

Bisphosphonates have become the standard first-line treatment for postmenopausal osteoporosis. This paper will trace the evolution of bisphosphonate therapies from daily to monthly or less frequent dosing regimens, outline evidence on efficacy, safety, and tolerability, and examine their potential to improve patient acceptance and clinical outcomes of osteoporosis treatment.

\section{Bisphosphonate pharmacology and dosing frequencies}

Two features of bisphosphonate structure determine biological activity (Figure 1). The arrangement of 2 phosphate groups bound to a geminal carbon (rather than an oxygen as in pyrophosphate) creates a non-hydrolyzable pyrophosphate analog (Rogers et al 2000), and the $R_{1}$ and $R_{2}$ groups occupying the carbon's other bonds mediate high-affinity calcium chelation. Thus, bisphosphonates are readily and tenaciously incorporated into bone mineral surfaces, where they are consumed by osteoclasts at remodeling sites.

Within osteoclasts, non-nitrogen-containing bisphosphonates are metabolized to apoptosis-inducing compounds. Nitrogen-containing bisphosphonates (the focus of this review) inhibit protein prenylation by farnesyl pyrophosphate synthase and thus disrupt the cellular physiology of resorption (Dunford et al 2001). Inhibitory potency, determined by the $\mathrm{R}_{2}$ group, is increased by tertiary nitrogen (as in ibandronate) or a heterocyclic ring (as in risedronate and zoledronic acid) (Dunford et al 2001). An upstream metabolite that accumulates during prenylation inhibition, isopentenyl pyrophosphate, is further metabolized to an apoptosisinducing product (Monkkonen et al 2007). Although osteoclast apoptosis is not essential for antiresorptive activity of

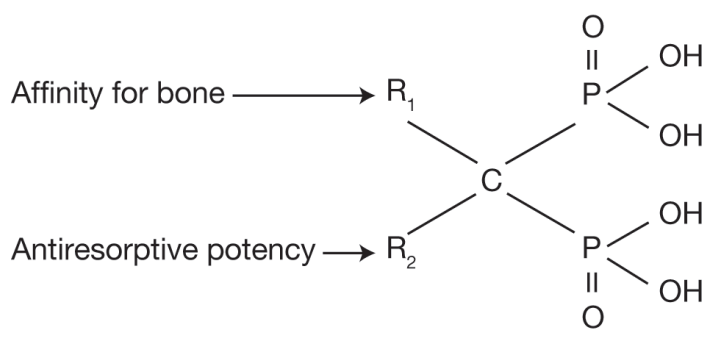

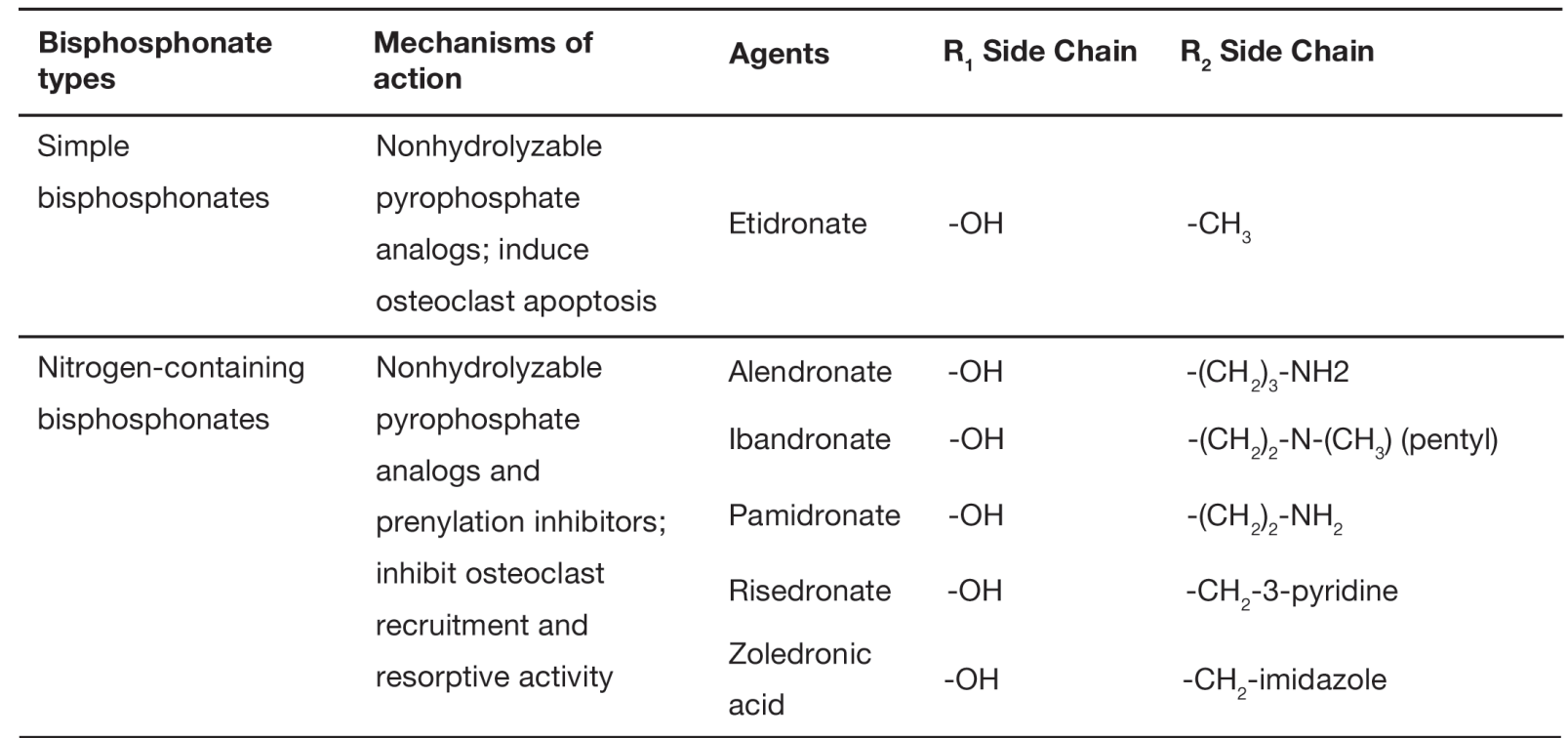

Figure I Bisphosphonate types and structures. 
nitrogen-containing bisphosphonates, it plays a contributory role (Russell et al 2008).

Suppression of bone turnover by nitrogen-containing bisphosphonates manifests in decreased serum and urine levels of bone turnover markers (Table 2). The bone collagen breakdown products cross-linked C-telopeptide (CTX) or N-telopeptide (NTX) are often used in clinical follow-up. The rate and magnitude of their decreases in response to treatment depend on bisphosphonate potency, dose, route, and interval.

\section{Evolution of dosing regimens}

Nitrogen-containing bisphosphonates have become the standard of care for osteoporosis. US approval dates for currently available bisphosphonate regimens are shown in Figure 2. Oral bisphosphonate dosing (daily, weekly, or monthly) is popular for first-line treatment in the outpatient setting. Intravenous (iv) regimens (quarterly or yearly), are newer options available to patients with postmenopausal osteoporosis. Intravenous bisphosphonates are particularly helpful for those who are bedfast or have esophageal disorders, cognitive problems, or other dosing challenges.

Alendronate, risedronate, and ibandronate all were initially approved by the Food and Drug Administration (FDA) for daily oral dosing, supported by trials with direct anti-fracture efficacy endpoints (Black et al 1996; Harris et al 1999; McClung et al 2001; Chesnut et al 2004). The burdensome dosing requirements needed for gastrointestinal (GI) protection with daily oral bisphosphonates have motivated development of less frequent oral regimens. Weekly dosing is made possible by the long half-life of bone-bound bisphosphonates, which remain at resorption sites longer than the 2-week lifespan of individual osteoclasts (Bone et al 2000). Weekly oral alendronate and risedronate achieved approval based on comparisons with the respective daily regimens (Schnitzer et al 2000; Brown et al 2002). Weekly oral ibandronate has also shown non-inferior efficacy to the daily regimen (Cooper et al 2003) but has not been marketed. These weekly regimens, with 7 times the daily oral dose, maintain continuous reduction of bone turnover markers (Papapoulos and Schimmer 2007).

Bisphosphonate pharmacology also makes possible monthly, intermittent, quarterly, or yearly dosing. In the quest for improved adherence and persistence, these extendedinterval regimens provide important lifestyle-friendly options. Monthly oral ibandronate, the first approved monthly bisphosphonate regimen, was supported by comparison trials with the daily regimen and has been in use since 2005 (Miller et al 2005; Reginster et al 2006). Pharmacodynamically, monthly oral ibandronate utilizes a non-linear dose increase versus the daily oral regimen ( $150 \mathrm{mg} / \mathrm{month}$ vs $2.5 \mathrm{mg} /$ day), which more than doubles annual cumulative skeletal exposure (ACE; $10.8 \mathrm{mg}$ with monthly vs $5.5 \mathrm{mg}$ with daily oral treatment) (Zaidi et al 2007). Increased ACE maintains efficacy during the interdose periods of extended-interval regimens (Zaidi et al 2007). Bone turnover markers show marked suppression within 3 days after a $150 \mathrm{mg} / \mathrm{month}$ oral ibandronate dose and reach a nadir by 7 days postdose (Silverman et al 2007a); although marker levels gradually increase during the interdose period, they remain throughout the month within the premenopausal range required for efficacy (Papapoulos and Schimmer 2007).

An intermittent oral risedronate regimen (2 consecutive days monthly) was approved in April 2007 (Delmas et al 2008a), and a once-monthly risedronate dosing regimen was approved in April 2008 (Delmas et al 2008b). These risedronate regimens provide 30 times the daily oral dose. Comparison to daily oral risedronate shows that they achieve similar bone turnover marker suppression and BMD increases (Delmas et al 2007a; Delmas et al 2007b).

Table 2 Biomarkers of bone turnover (After Leeming et al 2006)

\begin{tabular}{lll}
\hline Processes & Biomarkers & Descriptions \\
\hline Bone resorption & Bone type I collagen N-telopeptide & $\begin{array}{l}\text { Collagen breakdown product generated by osteoclast } \\
\text { cathepsin K } \\
\text { Collagen breakdown product generated by osteoclast } \\
\text { cathepsin K }\end{array}$ \\
& Deoxypyridinoline & $\begin{array}{l}\text { Collagen breakdown product; remnant of cross-links } \\
\text { of collagen polypeptides }\end{array}$ \\
& Tartrate-resistant alkaline phosphatase & Osteoclastic enzyme; may indicate osteoclast number \\
Bone formation & Bone-specific alkaline phosphatase & Osteoblastic enzyme involved in bone mineralization \\
& Osteocalcin & Major non-collagen protein of bone \\
Aminoterminal propeptide of type I procollagen & Byproduct of mature collagen formation \\
& Carboxyterminal propeptide of type I procollagen & Byproduct of mature collagen formation
\end{tabular}




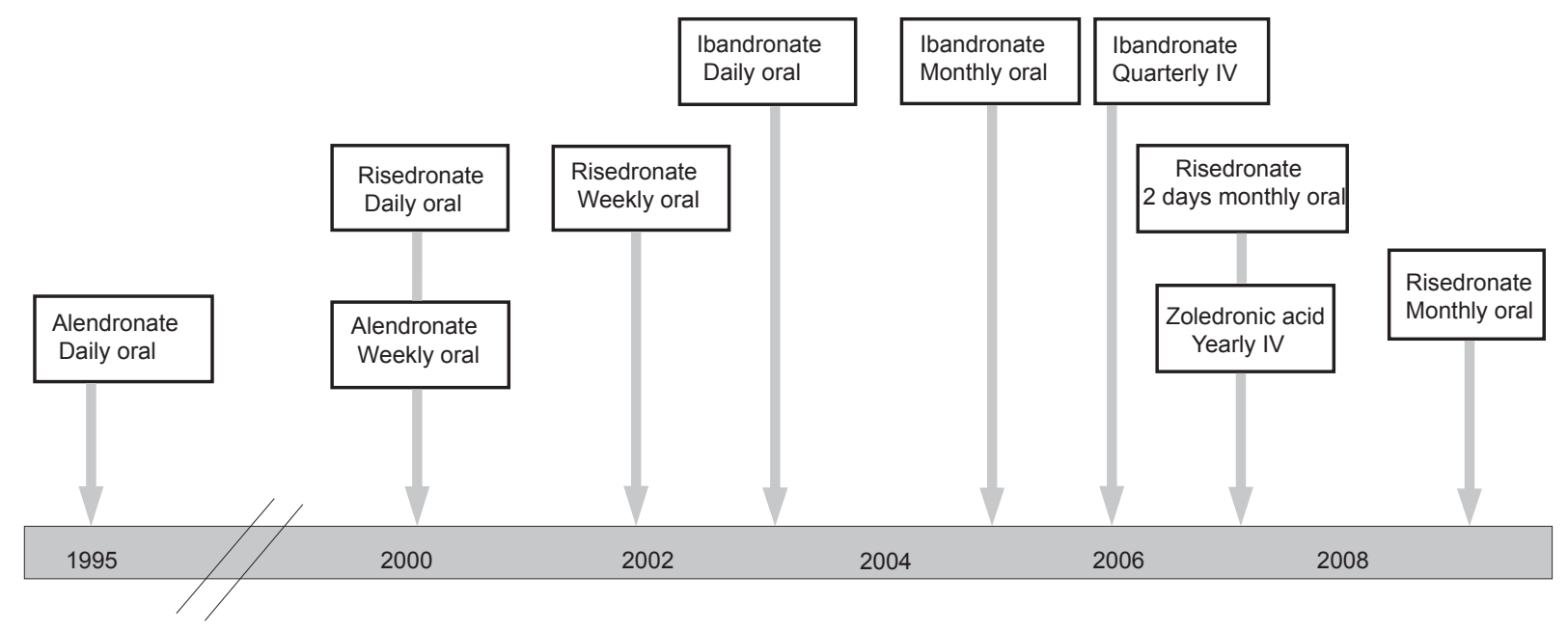

Figure 2 Timeline of Food and Drug Administration approvals of different bisphosphonate regimens.

Intravenous bisphosphonate regimens decouple bisphosphonate therapy from stringent oral dosing requirements, providing alternative options for any postmenopausal osteoporosis patients and extending the benefits of bisphosphonates to patients unable to take them orally. Quarterly iv ibandronate (3 mg/3 month), approved in 2006, has shown efficacy in postmenopausal osteoporosis with a similar safety profile to the monthly oral regimen (Delmas et al 2006). The lower-dose iv ibandronate regimens investigated during drug development did not achieve clinical efficacy because bone turnover returned toward untreated levels during the interdose periods (Adami et al 2004; Recker et al 2004). The approved $3 \mathrm{mg} / 3$ month iv dose provides the highest annual cumulative skeletal exposure of approved ibandronate regimens $(12 \mathrm{mg})$ (Zaidi et al 2007), resulting in superior efficacy to daily oral ibandronate (Eisman et al 2008).

Zoledronic acid was originally developed as a highpotency agent for single-dose iv infusion to treat hypercalcemia (Major 2002) and skeletal complications (Perry and Figgitt 2004) of malignancy. Suppression of bone turnover in osteopenic or osteoporotic postmenopausal women infused with $5 \mathrm{mg}$ zoledronic acid was more rapid and pronounced than in those receiving $70 \mathrm{mg} /$ week oral alendronate (Saag et al 2007); further investigations in postmenopausal osteoporosis led to the 2007 approval of a yearly iv zoledronic acid regimen ( $5 \mathrm{mg} /$ year) for this indication (Black et al 2007).

\section{Bisphosphonate efficacy, safety, and tolerability}

Key randomized trials evaluating nitrogen-containing bisphosphonates individually and comparatively are summarized in Table 3; their findings on efficacy, safety, and tolerability are described below.

\section{Efficacy studies}

Pivotal trials supporting approval of daily oral nitrogencontaining bisphosphonate regimens utilized fracturebased primary endpoints. After these daily regimens attained approval, "bridging trials" supporting less frequent dosing regimens were designed to show non-inferiority or equivalence to daily regimens by means of surrogate BMD endpoints.

\section{Daily oral regimens}

The Fracture Intervention Trial (FIT) evaluated oral alendronate $(5 \mathrm{mg} /$ day for the first 2 years; $10 \mathrm{mg} /$ day thereafter) vs placebo in women with (Black et al 1996) or without (Cummings et al 1998) baseline vertebral fractures. Alendronate reduced the relative risk of new vertebral fractures by roughly $50 \%$ in the group with prevalent vertebral fractures (Black et al 1996); hip and wrist fracture risks also decreased by roughly $50 \%$, and that of non-vertebral fractures by $20 \%$ (Table 2 ). In the group without baseline vertebral fractures (Cummings et al 1998), new vertebral fracture risk decreased by approximately $45 \%$; non-vertebral fracture effects depended on baseline BMD (Table 2).

In the FIT Long-term EXtension study (FLEX) (Bone et al 2004), FIT participants who received alendronate for 5 years were re-randomized to continue alendronate ( 5 or $10 \mathrm{mg} /$ day) or to switch to placebo for 5 additional years. In the group who received alendronate for a total of 10 years, BMD increased at multiple sites compared with baseline; lumbar spine BMD continued increasing throughout 


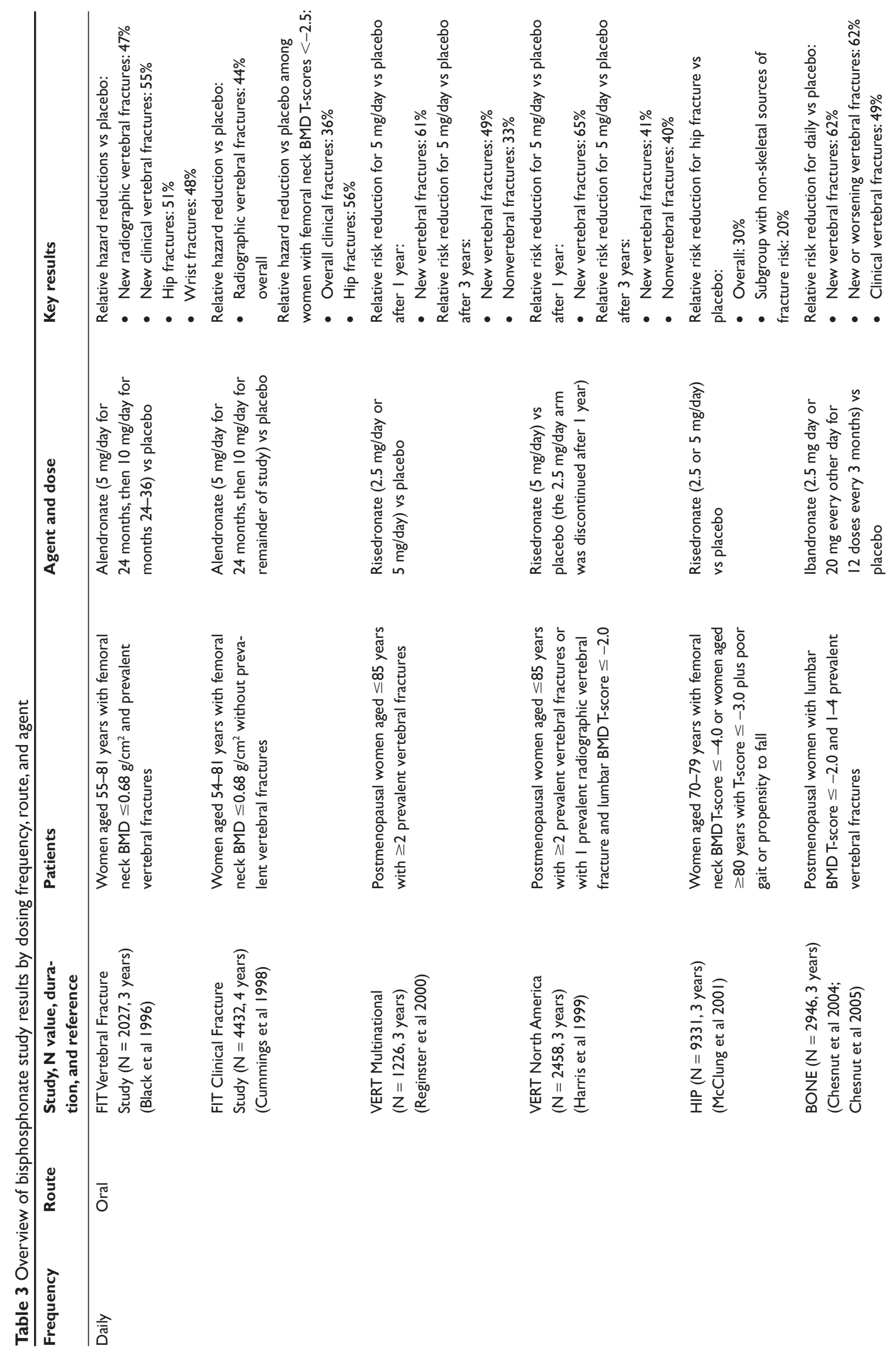



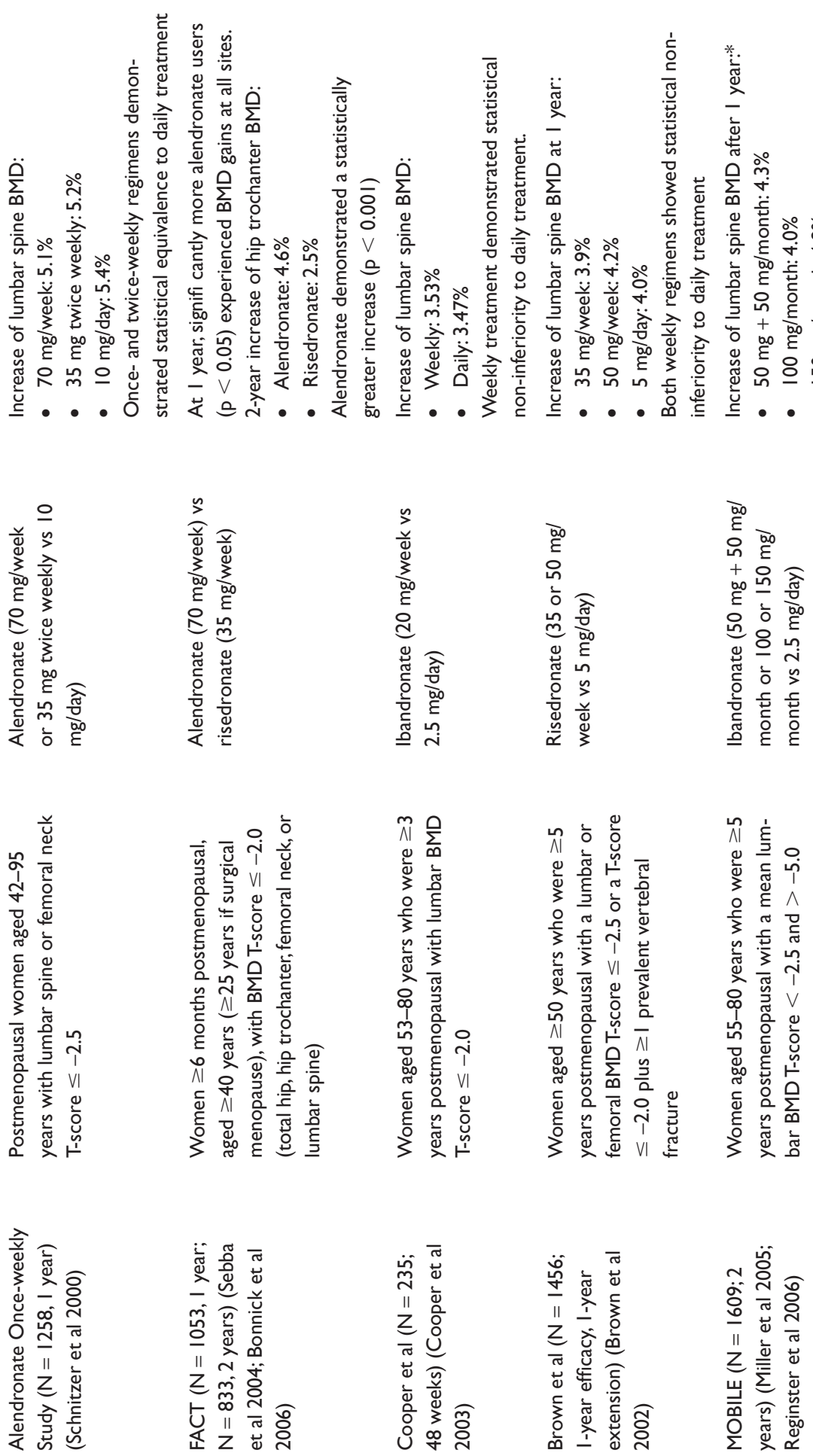

อั

ฮั

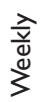






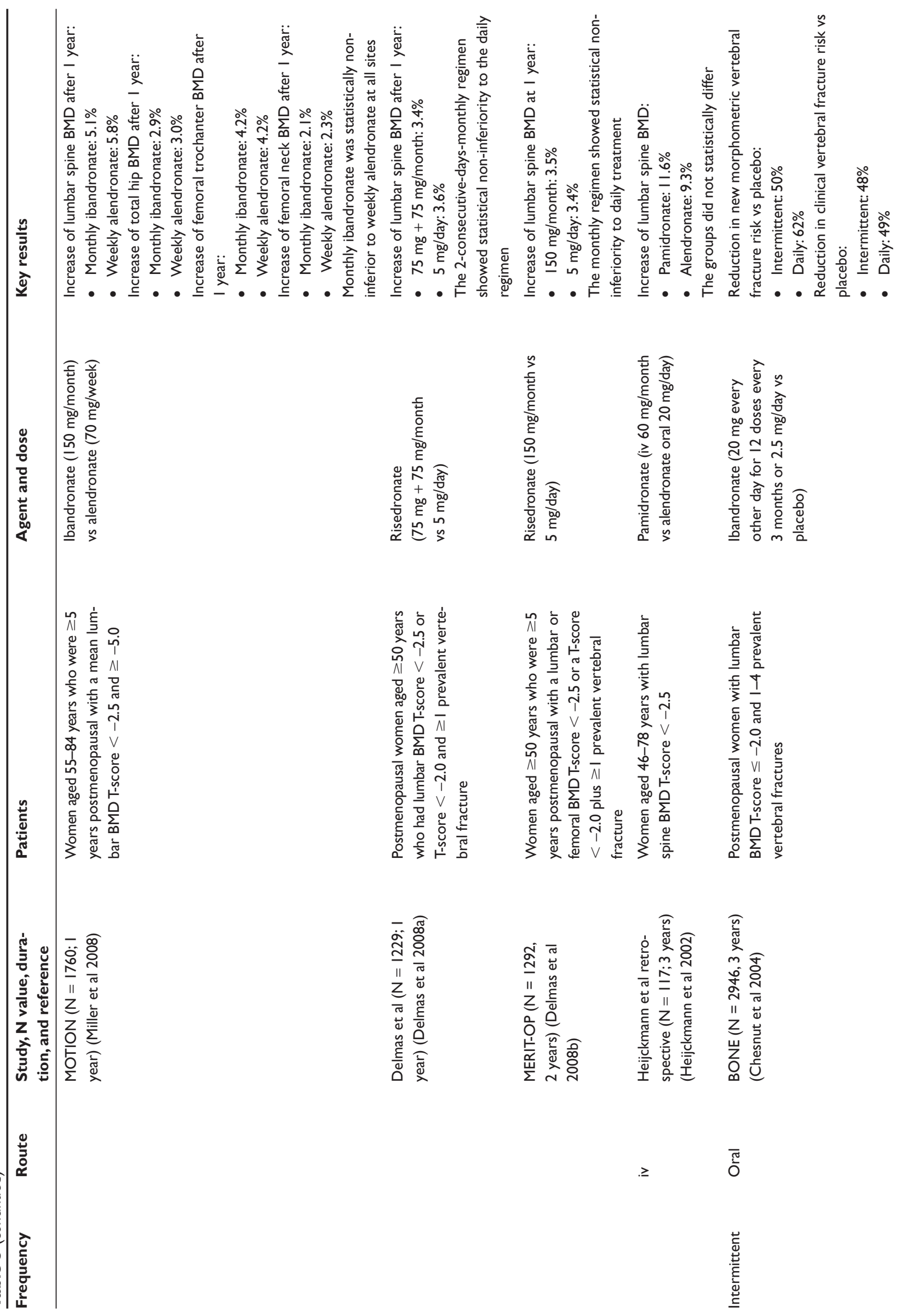





$\geq$

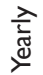


treatment, whereas from 5 years onward other sites showed stable or decreasing BMD (Bone et al 2004). Clinically evident vertebral fractures were less common than in the group who switched to placebo, who experienced hip and spine BMD declines after discontinuing alendronate (Black et al 2006).

Placebo-controlled trials supporting the approval of daily oral risedronate $(5 \mathrm{mg} /$ day) evaluated hip fractures among women with osteoporosis or non-skeletal risk factors (the Hip Intervention Program [HIP]) (McClung et al 2001) or new vertebral fractures among women with prevalent vertebral fractures (Vertebral Efficacy with Risedronate Trial [VERT]) (Reginster et al 2000). In HIP (McClung et al 2001), relative hip fracture risk was significantly reduced with risedronate vs placebo in the overall patient set and among osteoporotic patients, but did not differ significantly among non-osteoporotic patients with risk factors for falling (Table 2). Non-vertebral fracture risk, similarly, significantly decreased with risedronate overall and in osteoporotic patients. In the multinational VERT study (Reginster et al 2000), new vertebral fracture risk in risedronate recipients was reduced by $61 \%$ during the first year and by $49 \%$ over 3 years, whereas non-vertebral fracture risk was reduced by $33 \%$ over 3 years (Table 2). Risedronate recipients in the North American VERT study (Harris et al 1999) showed 1year vertebral fracture risk reduction of 65\%, 3-year vertebral fracture risk reduction of $41 \%$, and non-vertebral fracture risk reduction of $40 \%$ (Table 2).

In the oral iBandronate Osteoporosis vertebral fracture trial in North America and Europe (BONE) (Chesnut et al 2004), oral ibandronate given daily or intermittently to women with prevalent vertebral fractures significantly reduced the relative risk of new vertebral fractures and clinical vertebral fractures compared with placebo (Table 2). Lumbar BMD significantly increased and rates of height loss decreased in both ibandronate groups as compared with placebo (Chesnut et al 2004). Non-vertebral fracture risk also decreased by $69 \%$ in daily oral ibandronate recipients with low baseline femoral neck T-scores $<-3.0$ (Chesnut et al 2004). BONE supported the initial approval of daily oral ibandronate in 2005. Its vertebral fracture data provided the first evidence for anti-fracture efficacy of a non-daily oral bisphosphonate regimen.

\section{Weekly oral regimens}

In the Alendronate Once-Weekly Study (Schnitzer et al 2000), a $70 \mathrm{mg}$ oral once-weekly dose of alendronate resulted in statistically equivalent lumbar spine BMD gains to those seen with the $10 \mathrm{mg}$ daily treatment or $35 \mathrm{mg}$ twice-weekly treatment (Table 2); the $70 \mathrm{mg} /$ week oral alendronate regimen was approved in 2000. A bridging trial of risedronate at 35 or $50 \mathrm{mg} /$ week showed non-inferior increases of lumbar BMD with both regimens as compared with the $5 \mathrm{mg} /$ day approved dosing (Brown et al 2002), resulting in 2002 approval for $35 \mathrm{mg}$ weekly oral risedronate.

\section{Monthly oral regimens}

The currently available monthly oral ibandronate regimen was approved in 2005 on the basis of the 2-year Monthly Oral IBandronate in LadiEs (MOBILE) bridging trial (Miller et al 2005; Reginster et al 2006). In the MOBILE trial, monthly oral ibandronate regimens ( 100 or $150 \mathrm{mg} / \mathrm{month}$ ) proved as effective as the approved daily regimen at improving lumbar BMD (Table 2). The $150 \mathrm{mg} / \mathrm{month}$ regimen subsequently showed superiority to $100 \mathrm{mg} / \mathrm{month}$ and $2.5 \mathrm{mg} /$ day at lumbar spine and total hip BMD improvement (Miller et al 2005; Reginster et al 2006). Significantly greater percentages of patients achieved measurable 2-year BMD gains at lumbar spine, total hip, or both with the $150 \mathrm{mg} /$ month regimen vs $2.5 \mathrm{mg} /$ day $(\mathrm{p} \leq 0.004)$ or $100 \mathrm{mg} / \mathrm{month}(\mathrm{p}<0.01)$ (Reginster et al 2006). Additionally, $150 \mathrm{mg} / \mathrm{month}$ ibandronate resulted in significantly higher percentages of patients achieving target BMD gains ( $\geq 3 \%$ or $\geq 6 \%$ ) at these sites (Reginster et al 2006).

An oral risedronate regimen consisting of $75 \mathrm{mg}$ /day for 2 consecutive days monthly received US approval in April 2007, based on a bridging study showing its non-inferiority to the approved daily risedronate regimen (Table 2) (Delmas et al 2008a). The Monthly Evaluation of Risedronate Trial in OsteoPorosis (MERIT-OP) (Delmas et al 2008b) subsequently reported similar non-inferiority results for a $150 \mathrm{mg} / \mathrm{month}$ risedronate regimen approved in April 2008 (Table 2).

\section{Quarterly iv regimens}

Quarterly iv ibandronate received FDA approval in 2007 on the basis of the Intermittent Regimen iv Ibandronate Study (IRIS) (Adami et al 2004) and Dosing IV Administration (DIVA) (Delmas et al 2006; Eisman et al 2008) trials (Table 2), whose lumbar BMD endpoints demonstrated noninferiority to the approved daily oral ibandronate regimen. Both iv regimens in the DIVA trial achieved lumbar BMD increases statistically superior to oral dosing (Table 2) (Delmas et al 2006; Eisman et al 2008). Efficacy against non-vertebral fractures was subsequently demonstrated for the quarterly iv and monthly oral ibandronate regimens in pooled analyses (Cranney et al 2007; Harris et al 2008). 


\section{Yearly iv regimen}

The Health Outcomes and Reduced Incidence with Zoledronic Acid ONce Yearly (HORIZON) trial showed significant reduction of vertebral, non-vertebral, and hip fractures with yearly iv zoledronic acid vs placebo in post-menopausal osteoporosis patients with or without prevalent vertebral fractures (Table 2) (Black et al 2007). A subsequent study, the HORIZON Clinical Fracture Trial (Lyles et al 2007), included women and men who underwent surgical repair of low-trauma hip fractures within 90 days before enrollment. Yearly zoledronic acid recipients in this high-risk population showed relative risk reduction vs placebo of $35 \%$ in new clinical fractures and 28\% in 2-year all-cause mortality (Lyles et al 2007).

\section{Comparative trials}

The Fosamax Actonel Comparison Trial (FACT) (Bonnick et al 2006) compared weekly oral alendronate $(70 \mathrm{mg} /$ week $)$ and risedronate (35 mg/week) regimens in a 1-year head-tohead study with a 1-year extension (Table 2). At all time points alendronate produced significantly greater BMD increases than risedronate at the hip trochanter, lumbar spine, total hip, and femoral neck. Significantly more alendronate than risedronate recipients attained measurable BMD gains (Sebba et al 2004; Bonnick et al 2006). Fractures were reported only as adverse events (AEs) in the FACT studies.

The 1-year randomized, double-blind, double-dummy Monthly Oral Therapy with Ibandronate for Osteoporosis INtervention (MOTION) trial recently demonstrated that monthly oral ibandronate provides similar efficacy to weekly oral alendronate, as assessed by BMD improvements at the lumbar spine, total hip, trochanter, and femoral neck (Table 2) (Miller et al 2008). Fractures were reported only as AEs in the MOTION study.

\section{Meta-analyses of non-vertebral fracture efficacy}

The FDA requires direct anti-fracture endpoints to approve new bisphosphonate agents; initial trials are often designed and powered for primary endpoints of vertebral fracture. All approval trials for currently used nitrogen-containing bisphosphonates except HIP (risedronate) and HORIZON (zoledronic acid) were designed with primary vertebral fracture endpoints. In contrast, regimen extensions of existing agents can be approved on the basis of bridging trials. Thus, no direct anti-fracture efficacy trials exist for weekly, monthly, or quarterly bisphosphonates.

Non-vertebral fractures are infrequent events; their use as a trial endpoint requires large or high-risk populations and is affected by methodological variations (Miller 2008). Meta-analyses are thus often used to explore treatment effects on non-vertebral fracture risk. Daily alendronate has been associated in such meta-analyses with non-vertebral fracture risk reductions of 14\%-49\% (Karpf et al 1997; Cranney et al 2002b; Boonen et al 2005), and daily risedronate with nonvertebral fracture risk reductions of 19\%-59\% (Karpf et al 1997; Cranney et al 2002a; Harrington et al 2004; Liberman et al 2006). No currently published meta-analyses have specifically examined weekly oral bisphosphonate regimens.

Meta-analyses of extended-interval ibandronate regimens based on their achieved ACE have shown significant non-vertebral fracture risk reduction. Patients receiving $\mathrm{ACE} \geq 10.8 \mathrm{mg}$ (ie, approved monthly oral or quarterly iv ibandronate regimens or an investigational bimonthly iv regimen) achieved relative risk reductions versus placebo of $29.9 \%$ for all non-vertebral fractures, and $34.4 \%$ for a set of 6 important non-vertebral fractures (clavicle, humerus, wrist, pelvis, hip, leg) (Harris et al 2008). Ibandronate regimens with $\mathrm{ACE} \geq 10.8 \mathrm{mg}$ showed $38 \%$ relative risk reduction for all non-vertebral fractures versus daily oral ibandronate (ACE $5.5 \mathrm{mg}$ ) (Cranney et al 2008). These meta-analyses provide the first evidence of non-vertebral fracture efficacy for any weekly, monthly, or quarterly bisphosphonate regimen.

\section{Safety and tolerability}

The most common AEs reported with bisphosphonates affect the upper GI (UGI) system. In part such events may reflect the increased baseline incidence of UGI disorders among elderly patients and the synergistic effects of non-steroidal anti-inflammatory drugs (NSAIDs) used for comorbid arthritis. Adherence to oral dosing requirements (taking bisphosphonates with $\geq 8$ fluid oz $(237 \mathrm{~mL})$ water after an overnight fast and not reclining, eating, or drinking for 30-60 minutes after dosing) reduces UGI AEs and enhances absorption. AEs affecting other body systems are somewhat less frequent.

Oral ibandronate (daily or intermittent) shows UGI $\mathrm{AE}$ frequencies similar to placebo, even among patients with histories of UGI disorders or concomitant anti-ulcer or NSAID treatment (Epstein et al 2006). Head-to-head studies indicate that safety and tolerability profiles, and in particular UGI tolerability, appear not to vary greatly among different oral bisphosphonates. In the FACT (Bonnick et al 2006), overall AEs, serious AEs, and discontinuations due to AEs were similar between $70 \mathrm{mg} /$ week alendronate and $35 \mathrm{mg} /$ week risedronate. UGI AEs (predominantly dyspepsia, nausea, and reflux) affected $24.8 \%$ of alendronate recipients 
and $22.9 \%$ of risedronate recipients; and $1.7 \%$ and $1.2 \%$, respectively, discontinued because of UGI AEs (Bonnick et al 2006). In the MOTION trial (Delmas et al 2007b), the incidence of UGI AEs was similar between weekly oral alendronate (17.2\%) and monthly oral ibandronate (17.5\%); however, more alendronate users withdrew because of treatment-related UGI AEs (1.7\% vs $1.0 \%$ of ibandronate users). Because UGI AEs generally result from topical irritation, agents designed for less frequent oral dosing may reduce cumulative risk (Epstein et al 2006).

Osteonecrosis of the jaw (ONJ) is an infrequent but troublesome bisphosphonate-related $\mathrm{AE}$ thought to result from antiangiogenesis (Migliorati 2003; Migliorati et al 2006), impaired circulation, or excessive osteoclast suppression (Carter et al 2005). Most ONJ reports are associated with iv pamidronate or zoledronic acid prescribed for hypercalcemia of malignancy or skeletal metastases (indications requiring higher and more frequent doses than are used in osteoporosis). Cumulative worldwide ONJ reports with oral bisphosphonates (as of 2006) have included 170 with alendronate, 12 with risedronate and a single patient who had received both ibandronate and iv zoledronic acid (American Dental Association Council on Scientific Affairs 2006). A 2007 systematic review (Pazianas et al 2007) collected 26 ONJ cases in adult osteoporosis patients receiving bisphosphonates (alendronate, 23; alendronate and zoledronic acid, 1; pamidronate, 1 ; risedronate, 1 ; ibandronate, 0). Advancing age, dental extractions, and corticosteroid use showed significant associations with ONJ risk.

Reports of atrial fibrillation in trials of yearly iv zoledronic acid (Black et al 2007) and daily oral alendronate (Cummings et al 2007) recently prompted an FDA safety review of this $\mathrm{AE}$ among bisphosphonate users (Food and Drug Administration 2007). Although serious atrial fibrillation events in these studies (Black et al 2007; Cummings et al 2007) were significantly more frequent in drug recipients, no significant difference was seen between bisphosphonates and placebo when all atrial fibrillation events were considered. Neither serious nor overall atrial fibrillation events significantly differed between zoledronic acid and placebo in the HORIZON Recurrent Fracture trial, which enrolled an older patient population than the pivotal HORIZON study (Lyles et al 2007). Postdose electrolyte imbalances (hypocalcemia, hypophosphatemia, or hypomagnesemia) have been suggested to be responsible for atrial fibrillation during bisphosphonate use (de Nijs and Westgeest 2007; Poole et al 2007); however, the causality of this AE is not known with certainty. An October 2007 early communication about the ongoing safety review stated that bisphosphonate prescribing patterns need not change at this time (Food and Drug Administration 2007).

Reduced kidney function has been reported in $9 \%$ to $15 \%$ of patients receiving iv zoledronic acid or pamidronate (Chang et al 2003). In the HORIZON trial (Black et al 2007), increases of serum creatinine $>0.5 \mathrm{~g} / \mathrm{dL}$ occurred at 9-11 days postdose in significantly more zoledronic acid recipients (iv $5 \mathrm{mg} /$ year $)$ than placebo recipients $(1.2 \%$ vs $0.4 \%, \mathrm{p}=0.001)$. In $85 \%$ of cases, levels reverted in 30 days to within $0.5 \mathrm{~g} / \mathrm{dL}$ of baseline, and by the third year of the study, there was no significant difference between study groups. Although iv ibandronate labeling includes a precaution regarding hypocalcemia and renal impairment, iv ibandronate has shown no evidence of affecting renal function in patients with cancerrelated bone disease (Strampel et al 2007) or in DIVA trial participants (Rizzoli and Reid 2007). In a pooled analysis of 4 trials comprising 6815 patients with osteoporosis and estimated glomerular filtration rates $>30 \mathrm{~mL} / \mathrm{min} / 1.73 \mathrm{~m}^{2}$, changes in estimated creatinine clearance throughout study duration were modest and similar among iv ibandronate, daily oral ibandronate, and placebo groups (Miller et al 2007). Patients receiving iv bisphosphonate medications should have their serum creatinine measured regularly.

Ocular inflammatory AEs (conjunctivitis, episcleritis, uveitis, or scleritis) are occasionally associated with nitrogencontaining bisphosphonates (particularly with regimens used in cancer) and may be mediated by tumor necrosis factor- $\alpha$ and interleukins 1 and 6 (Fraunfelder 2003; Fraunfelder 2007). Patients experiencing eye pain during bisphosphonate use require immediate referral to an ophthalmologist. Conjunctivitis and episcleritis may be treated topically; uveitis and scleritis require bisphosphonate discontinuation (Fraunfelder 2003; Fraunfelder 2007).

A transient flu-like illness (fever, myalgia, arthralgia, and malaise) may occur upon initial bisphosphonate use (especially with iv use or the oral dose levels used in monthly or intermittent treatment) and is thought to represent an acute phase reaction to accumulated by-products of prenylation inhibition (Bukowski et al 2005). Generally, symptoms are mild, last only 1-3 days, and diminish in incidence and severity with subsequent doses.

\section{Patient perspectives: improving treatment uptake, adherence, and persistence}

Osteoporosis prevention is a lifelong endeavor, and osteoporosis treatment ideally starts at or before the initial 
BMD decline after menopause. Care of elderly patients presenting with incident fractures must go beyond emergent repair to assessment and reduction of recurrent fracture risk. In one Midwestern community care system, process improvements utilizing follow-up of orthopedic billings provided osteoporosis evaluation and treatment to $58 \%$ of incident fragility fracture patients in 2003 , in contrast to only $5 \%$ in 1999 (Harrington et al 2005). Patients with incident hip or spine fractures face increased future fracture risk (Black et al 1999; Lindsay et al 2001) as well as acute risk of disability and mortality. Treating underlying osteoporosis in such patients may conserve medical and financial resources, functional capacity, and life expectancy.

The achievement and maintenance of fracture prevention benefits requires continuity of osteoporosis treatment. Unfortunately, adherence and persistence with treatment are problematic in all chronic diseases and pose particular challenges in osteoporosis. Oral bisphosphonate dosing requirements are inconvenient for patients; thus, less frequent treatment intervals are conducive to better patient acceptance, adherence, and persistence. The US Surgeon General's Report on Bone Health and Osteoporosis (US Department of Health and Human Services 2004) has highlighted the need for interventions that improve adherence and for research specifically exploring the impact of dosing regimens on adherence. By making therapy less intrusive to daily life, oral regimens with less frequent dosing may provide improved real-world effectiveness.

\section{Patient preferences and adherence: obstacles and opportunities}

Patient inconvenience in osteoporosis treatment is not just a nuisance but a real hazard to effective clinical outcomes, as disruption of maintenance regimens can have severe physical consequences. Premature discontinuation of bisphosphonate therapy has been associated with up to $26 \%$ increase in fracture risk (Chesnut 2006; Gold et al 2007), and frequent oral dosing strongly predicts earlier discontinuation (Cramer et al 2005). Adherence and persistence with bisphosphonate therapy are important not only for direct anti-fracture benefits, but also for reduced overall healthcare requirements. In a retrospective study of 32,944 women initiating bisphosphonate treatment, those remaining adherent and persistent had significantly lower total healthcare costs than those with gaps or discontinuation of therapy (Curtis et al 2006). Adherence to weekly dosing is improved over daily regimens (Cramer et al 2005; Gold et al 2007), but remains suboptimal. Only $45 \%$ of weekly bisphosphonate recipients in a large longitudinal study maintained adherence and only 57\% maintained persistence over 1 year (Chesnut 2006). Thus, though once-weekly therapy represents a move toward a more patient-friendly regimen, it still presents obstacles to sustained treatment.

Once-monthly oral ibandronate may reduce the cumulative inconvenience of an oral bisphosphonate regimen and help patients maintain continuity of treatment. Once-monthly ibandronate users in 2 recent retrospective database studies $(\mathrm{N}=17,479$ and $\mathrm{N}=11,664)$ were respectively $25.1 \%$ and $37.7 \%$ less likely than once-weekly oral bisphosphonate users to discontinue therapy before 1 year (Silverman et al 2007b). The naturalistic PERsistence Study of Ibandronate verSus alendronaTe (PERSIST) study in the UK (Cooper et al 2006) compared persistence times among women in primary care randomized to 6 months of open-label treatment with monthly oral ibandronate or weekly oral alendronate. Ibandronate recipients were offered a patient support program (PSP) available to all UK patients prescribed ibandronate; no similar program existed at the time of the study for alendronate users in the community. Kaplan-Meier analysis showed a significantly higher probability of persistence in the ibandronate/PSP group ( $p<0.0001)$; mean $( \pm \mathrm{SD})$ persistence times were $122 \pm 2.5$ days for ibandronate/PSP and $109 \pm 2.5$ days for alendronate (Cooper et al 2006). However, conflicting results are reported in different persistence comparisons (Weiss et al 2007). Once-monthly ibandronate was preferred over once-weekly alendronate by $66.1 \%$ of patients in the randomized, crossover Boniva Alendronate Trial in Osteoporosis (Emkey et al 2005).

Patients who cannot tolerate or do not prefer oral dosing may opt for quarterly iv ibandronate injection (Rizzoli and Reid 2007) or yearly iv zoledronic acid infusion (Black et al 2007). These regimens abrogate oral dosing requirements, but require periodic visits to a physician's office or infusion center for administration. Outpatients with adverse GI histories on daily or weekly oral bisphosphonates achieved improved adherence to quarterly iv ibandronate (Lewiecki et al 2008). Yearly iv zoledronic acid has been preferred by a majority of trial outpatients who switched to it from weekly oral alendronate (McClung et al 2007; Saag et al 2007). Intravenous regimens may be particularly advantageous for elderly patients residing in long-term care facilities or those with impairments affecting medication self-management. The availability of multiple oral and iv options gives patients the opportunity to decide which attributes of a bisphosphonate regimen they consider most important for long-term sustainability. 


\section{Physiologic assessments of adherence and response}

The clinical silence of osteoporosis until fractures occur may create challenges in sustaining patients' motivation for treatment. BMD change is clinically measured no more often than every 2 years (Bonnick and Shulman 2006). Earlier demonstration of therapeutic response may help to motivate patients and to detect non-adherence. Biomarkers of bone turnover (Table 2), measured in serum or urine, change much more rapidly than BMD (Bonnick and Shulman 2006), and thus may provide early objective feedback on adherence and response. Decreased CTX at various time points during bisphosphonate therapy is strongly correlated with BMD increases at 6 months and 1 year (Leeming et al 2006). Conversely, high CTX levels may predict fracture risk; in the Epidemiology of Osteoporosis study (Garnero et al 1996a), elderly women with elevated urinary CTX had a 4.8-fold increased risk of hip fractures.

Patients' responses to biomarker-based feedback showed unexpected patterns in a 1-year prospective study of risedronate treatment $(5 \mathrm{mg} /$ day orally for 1 year) with and without a reinforcement program (urinary NTX testing and patient education at weeks 13 and 25) (Delmas et al 2007a). In addition to the biomarker follow-up, persistence was measured directly with electronically monitored pill dispensers; overall persistence over 1 year was $77 \%$ in the reinforcement group and $80 \%$ in the non-reinforcement group. Counterintuitively, patients who were informed of a poor NTX response $(>30 \%$ increase, indicating poor adherence) were roughly twice as likely to discontinue therapy prematurely. In contrast, patients informed of a good NTX response ( $>30 \%$ decrease) showed improved persistence rates after the reinforcement visit (Delmas et al 2007a). Patients in the reinforcement group had less than half the incidence of new vertebral fractures as in the non-reinforcement group. Interventions that increase persistence with bisphosphonates improve fracture protection.

Recent developments thus allow a multipronged approach to maintaining the continuity of bisphosphonate treatment. Monthly or less frequent regimens lessen lifestyle disruption, preference assessments identify the attributes patients value, and bone turnover markers provide physiologic accountability.

\section{Conclusions}

Nitrogen-containing bisphosphonates have become the standard of care for postmenopausal osteoporosis, in company with calcium and vitamin D supplementation and weightbearing physical activity. Oral bisphosphonate dosing requires stringent dosing guidelines to maximize bioavailability and minimize UGI irritation. The inconvenience this poses to patients has motivated the development of weekly and monthly oral regimens to enhance adherence, as well as quarterly and yearly iv regimens for patients unable to tolerate oral dosing. Ibandronate is the first bisphosphonate to have shown direct anti-fracture efficacy with a non-daily regimen; it was approved for once-monthly oral dosing in 2005 and for quarterly iv dosing in 2006. Yearly iv zoledronic acid was approved in 2007; it has shown improvement of fracture rates and post-fracture mortality, although the recent FDA early communication about atrial fibrillation and bisphosphonate use certainly warrants ongoing safety review. The availability of once-monthly and less frequent bisphosphonate regimens promises to improve patient satisfaction and adherence, and thus to increase the real-world effectiveness of osteoporosis therapy.

\section{Acknowledgments}

The author acknowledges Kim Coleman Healy, PhD, of Envision Pharma for editorial assistance in the development of this manuscript. This editorial assistance was supported by an independent grant from Roche.

\section{Disclosures}

The author's financial relationships over the past 12 months include research support from GlaxoSmithKline and Roche, speakers' bureau membership for GlaxoSmithKline, Roche, and Ortho-McNeil, and consulting for Novartis.

\section{References}

Adami S, Felsenberg D, Christiansen C, et al. 2004. Efficacy and safety of ibandronate given by intravenous injection once every 3 months. Bone, 34:881-9.

American Dental Association Council on Scientific Affairs. 2006. Dental management of patients receiving oral bisphosphonate therapy: expert panel recommendations. J Am Dent Assoc, 137:1144-50.

Bischoff-Ferrari HA, Willett WC, Wong JB, et al. 2005. Fracture prevention with vitamin D supplementation: a meta-analysis of randomized controlled trials. JAMA, 293:2257-64.

Black DM, Arden NK, Palermo L, et al. 1999. Prevalent vertebral deformities predict hip fractures and new vertebral deformities but not wrist fractures. Study of Osteoporotic Fractures Research Group. J Bone Miner Res, 14:821-8.

Black DM, Cummings SR, Karpf DB, et al. 1996. Randomised trial of effect of alendronate on risk of fracture in women with existing vertebral fractures. Fracture Intervention Trial Research Group. Lancet, 348:1535-41.

Black DM, Delmas PD, Eastell R, et al. 2007. Once-yearly zoledronic acid for treatment of postmenopausal osteoporosis. $N$ Engl $\mathrm{J} \mathrm{Med,}$ 356:1809-22.

Black DM, Schwartz AV, Ensrud KE, et al. 2006. Effects of continuing or stopping alendronate after 5 years of treatment: the Fracture Intervention Trial Long-term Extension (FLEX): a randomized trial. JAMA, 296:2927-38. 
Bone HG, Adami S, Rizzoli R, et al. 2000. Weekly administration of alendronate: rationale and plan for clinical assessment. Clin Ther, 22:15-28.

Bone HG, Hosking D, Devogelaer JP, et al. 2004. Ten years' experience with alendronate for osteoporosis in postmenopausal women. $N$ Engl J Med, 350:1189-99.

Bonnick S, Saag KG, Kiel DP, et al. 2006. Comparison of weekly treatment of postmenopausal osteoporosis with alendronate versus risedronate over two years. J Clin Endocrinol Metab, 91:2631-7.

Bonnick SL, Shulman L. 2006. Monitoring osteoporosis therapy: bone mineral density, bone turnover markers, or both? Am J Med, 119(4 Suppl 1):S25-S31.

Boonen S, Laan RF, Barton IP, et al. 2005. Effect of osteoporosis treatments on risk of non-vertebral fractures: review and meta-analysis of intention-to-treat studies. Osteoporos Int, 16:1291-8.

Briot K, Roux C. 2005. What is the role of DXA, QUS and bone markers in fracture prediction, treatment allocation and monitoring? Best Pract Res Clin Rheumatol, 19:951-64.

Brown JP, Kendler DL, McClung MR, et al. 2002. The efficacy and tolerability of risedronate once a week for the treatment of postmenopausal osteoporosis. Calcif Tissue Int, 71:103-11.

Bukowski JF, Dascher CC, Das H. 2005. Alternative bisphosphonate targets and mechanisms of action. Biochem Biophys Res Commun, 328:746-50.

Burge R, Dawson-Hughes B, Solomon DH, et al. 2007. Incidence and economic burden of osteoporosis-related fractures in the United States, 2005-2025. J Bone Miner Res 22:465-75.

Carter G, Goss AN, Doecke C. 2005. Bisphosphonates and avascular necrosis of the jaw: a possible association. Med J Aust, 182:413-5.

Chang JT, Green L, Beitz J. 2003. Renal failure with the use of zoledronic acid [letter]. N Engl J Med, 349:1676-9; discussion 1676-9.

Chesnut CH. 2006. Treating osteoporosis with bisphosphonates and addressing adherence: a review of oral ibandronate. Drugs, 66:1351-9.

Chesnut CH, Ettinger MP, Miller PD, et al. 2005. Ibandronate produces significant, similar antifracture efficacy in North American and European women: new clinical findings from BONE. Curr Med Res Opin, 21:391-401.

Chesnut CH, Skag A, Christiansen C, et al. 2004. Effects of oral ibandronate administered daily or intermittently on fracture risk in postmenopausal osteoporosis. J Bone Miner Res, 19:1241-9.

Cooper A, Drake J, Brankin E. 2006. Treatment persistence with once-monthly ibandronate and patient support vs. once-weekly alendronate: results from the PERSIST study. Int $J$ Clin Pract, 60:896-905.

Cooper C, Emkey RD, McDonald RH, et al. 2003. Efficacy and safety of oral weekly ibandronate in the treatment of postmenopausal osteoporosis. $J$ Clin Endocrinol Metab, 88:4609-15.

Cramer JA, Amonkar MM, Hebborn A, et al. 2005. Compliance and persistence with bisphosphonate dosing regimens among women with postmenopausal osteoporosis. Curr Med Res Opin, 21:1453-60.

Cranney A, Tugwell P, Adachi J, et al. 2002a. Meta-analyses of therapies for postmenopausal osteoporosis. III. Meta-analysis of risedronate for the treatment of postmenopausal osteoporosis. Endocr Rev, 23:517-23.

Cranney A, Wells G, Yetisir E, et al. 2008. Ibandronate for the prevention of nonvertebral fractures: a pooled analysis of individual patient data. Osteoporos Int, Epub ahead of print July 29, 2008.

Cranney A, Wells G, Willan A, et al. 2002b. Meta-analyses of therapies for postmenopausal osteoporosis. II. Meta-analysis of alendronate for the treatment of postmenopausal women. Endocr Rev, 23:508-16.

Cummings SR, Black DM, Thompson DE, et al. 1998. Effect of alendronate on risk of fracture in women with low bone density but without vertebral fractures: results from the Fracture Intervention Trial. JAMA, 280:2077-82.

Cummings SR, Schwartz AV,Black DM. 2007. Alendronate and atrial fibrillation. $N$ Engl J Med, 356:1895-6.
Curtis JR, Amonkar MM, Mucha L, et al. 2006. Osteoporotic women adherent to bisphosphonates have reduced osteoporosis-related and total healthcare costs. Poster SU 320. Twenty-eighth annual meeting of the American Society for Bone and Mineral Research, Philadelphia, PA, USA, presented September 17, 2006.

de Nijs RN, Westgeest AA. 2007. Yearly zoledronic acid in postmenopausal osteoporosis [letter]. $N$ Engl J Med, 357:711; author reply 714-5.

Delmas PD, Adami S, Strugala C, et al. 2006. Intravenous ibandronate injections in postmenopausal women with osteoporosis: One-year results from the dosing intravenous administration study. Arthritis Rheum, 54:1838-46.

Delmas PD, Vrijens B, Eastell R, et al. 2007a. Effect of monitoring bone turnover markers on persistence with risedronate treatment of postmenopausal osteoporosis. J Clin Endocrinol Metab, 92:1296-304.

Delmas PD, Lewiecki EM, Ragi-Eis S, et al. 2007b. The MOTION study: tolerability of monthly ibandronate and weekly alendronate in women with postmenopausal osteoporosis. Abstract T383, J Bone Miner Res, 22(Suppl 1):S327.

Delmas PD, Benhamou CL, Man Z, et al. 2008a. Monthly dosing of $75 \mathrm{mg}$ risedronate on 2 consecutive days a month: efficacy and safety results. Osteoporos Int, 19:1039-45.

Delmas PD, McClung MR, Zanchetta JR, et al. 2008b. Efficacy and safety of risedronate $150 \mathrm{mg}$ once a month in the treatment of postmenopausal osteoporosis. Bone, 42:36-42.

Dunford JE, Thompson K, Coxon FP, et al. 2001. Structure-activity relationships for inhibition of farnesyl diphosphate synthase in vitro and inhibition of bone resorption in vivo by nitrogen-containing bisphosphonates. J Pharmacol Exp Ther, 296:235-42.

Eisman JA, Civitelli R, Adami S, et al. 2008. Efficacy and tolerability of intravenous ibandronate injections in postmenopausal osteoporosis: 2-year results from the DIVA study. J Rheumatol, 35:488-97.

Emkey R, Koltun W, Beusterien K, et al. 2005. Patient preference for oncemonthly ibandronate versus once-weekly alendronate in a randomized, open-label, cross-over trial: the Boniva Alendronate Trial in Osteoporosis (BALTO). Curr Med Res Opin, 21:1895-903.

Epstein S, Delmas PD, Emkey R, et al. 2006. Oral ibandronate in the management of postmenopausal osteoporosis: review of upper gastrointestinal safety. Maturitas, 54:1-10.

Food and Drug Administration. 2007. Early communication of an ongoing safety review. Bisphosphonates: Alendronate (Fosamax, Fosamax Plus D), Etidronate (Didronel), Ibandronate (Boniva), Pamidronate (Aredia), Risedronate (Actonel, Actonel w/Calcium), Tiludronate (Skelid) and Zoledronic acid (Reclast, Zometa) [online]. Accessed October 30, 2007. URL: http://www.fda.gov/cder/drug/early_comm/ bisphosphonates.htm.

Fraunfelder FW. 2003. Ocular side effects associated with bisphosphonates. Drugs Today (Barc), 39:829-35.

Fraunfelder FW. 2007. Drug-induced ocular inflammatory diseases. Drugs Today (Barc), 43:117-23.

Garnero P, Hausherr E, Chapuy MC, et al. 1996a. Markers of bone resorption predict hip fracture in elderly women: the EPIDOS Prospective Study. J Bone Miner Res, 11:1531-8.

Garnero P, Sornay-Rendu E, Chapuy MC, et al. 1996b. Increased bone turnover in late postmenopausal women is a major determinant of osteoporosis. J Bone Miner Res, 11:337-49.

Gold DT, Martin BC, Frytak JR, et al. 2007. A claims database analysis of persistence with alendronate therapy and fracture risk in post-menopausal women with osteoporosis. Curr Med Res Opin, 23:585-94.

Harrington JT, Barash HL, Day S, et al. 2005. Redesigning the care of fragility fracture patients to improve osteoporosis management: a health care improvement project. Arthritis Rheum, 53:198-204.

Harrington JT, Ste-Marie LG, Brandi ML, et al. 2004. Risedronate rapidly reduces the risk for nonvertebral fractures in women with postmenopausal osteoporosis. Calcif Tissue Int, 74:129-35.

Harris ST, Blumentals WA, Miller PD. 2008. Ibandronate and the risk of non-vertebral and clinical fractures in women with postmenopausal osteoporosis: results of a meta-analysis of phase III studies. Curr Med Res Opin, 24:237-45. 
Harris ST, Watts NB, Genant HK, et al. 1999. Effects of risedronate treatment on vertebral and nonvertebral fractures in women with postmenopausal osteoporosis: a randomized controlled trial. Vertebral Efficacy With Risedronate Therapy (VERT) Study Group. JAMA, 282:1344-52.

Healy BP. 1998. Weak and feeble bones no more: the National Osteoporosis Foundation speaks out. $J$ Womens Health, 7:1067-8.

Heijckmann AC, Juttmann JR, Wolffenbuttel BH. 2002. Intravenous pamidronate compared with oral alendronate for the treatment of postmenopausal osteoporosis. Neth J Med, 60:315-9.

Hodgson SF, Watts NB, Bilezikian JP, et al. 2001. American Association of Clinical Endocrinologists 2001 Medical Guidelines for Clinical Practice for the Prevention and Management of Postmenopausal Osteoporosis. Endocr Pract, 7:293-312.

Kanis JA. 2008. FRAX ${ }^{\mathrm{TM}}$ WHO Fracture Risk Assessment Tool [online]. Accessed March 3, 2008. URL: http://www.shef.ac.uk/FRAX/ index.htm

Kanis JA, Oden A, Johnell O, et al. 2007. The use of clinical risk factors enhances the performance of BMD in the prediction of hip and osteoporotic fractures in men and women. Osteoporos Int, 18:1033-46.

Karpf DB, Shapiro DR, Seeman E, et al. 1997. Prevention of nonvertebral fractures by alendronate. A meta-analysis. Alendronate Osteoporosis Treatment Study Groups. JAMA, 277:1159-64.

Leeming DJ, Alexandersen P, Karsdal MA, et al. 2006. An update on biomarkers of bone turnover and their utility in biomedical research and clinical practice. Eur J Clin Pharmacol, 62:781-92.

Lewiecki EM, Babbitt AM, Piziak VK, et al. 2008. Adherence and gastrointestinal tolerability to monthly oral or quarterly intravenous ibandronate in patients with prior gastrointestinal intolerance to oral bisphosphonates: A 12-month, open-label prospective evaluation. Clin Ther, 30:605-21.

Liberman UA, Hochberg MC, Geusens P, et al. 2006. Hip and non-spine fracture risk reductions differ among antiresorptive agents: Evidence from randomised controlled trials. Int J Clin Pract, 60:1394-400.

Lindsay R, Silverman SL, Cooper C, et al. 2001. Risk of new vertebral fracture in the year following a fracture. JAMA, 285:320-3.

Lyles KW, Colon-Emeric CS, Magaziner JS, et al. 2007. Zoledronic acid and clinical fractures and mortality after hip fracture. $N$ Engl J Med, 357:1799-809.

MacLean C, Newberry S, Maglione M, et al. 2008. Systematic review: comparative effectiveness of treatments to prevent fractures in men and women with low bone density or osteoporosis. Ann Intern Med, 148:197-213.

Major P. 2002. The use of zoledronic acid, a novel, highly potent bisphosphonate, for the treatment of hypercalcemia of malignancy. Oncologist, 7:481-91.

McClung M, Recker R, Miller P, et al. 2007. Intravenous zoledronic acid $5 \mathrm{mg}$ in the treatment of postmenopausal women with low bone density previously treated with alendronate. Bone, 41:122-8.

McClung MR, Geusens P, Miller PD, et al. 2001. Effect of risedronate on the risk of hip fracture in elderly women. Hip Intervention Program Study Group. N Engl J Med, 344:333-40.

Migliorati CA. 2003. Bisphosphonates and oral cavity avascular bone necrosis. J Clin Oncol, 21:4253-4.

Migliorati CA, Siegel MA, Elting LS. 2006. Bisphosphonate-associated osteonecrosis: a long-term complication of bisphosphonate treatment. Lancet Oncol, 7:508-14.

Miller PD. 2008. Non-vertebral fracture risk reduction with oral bisphosphonates: challenges with interpreting clinical trial data. Curr Med Res Opin, 24:107-19.

Miller PD, Epstein S, Sedarati F, et al. 2008. Once-monthly oral ibandronate compared with weekly oral alendronate in postmenopausal osteoporosis: results from the head-to-head MOTION study. Curr Med Res Opin, 24:207-13.

Miller PD, Lewiecki EM, Zaidi M. 2007. IV ibandronate injections demonstrate favorable renal tolerability [abstract 297]. American Association of Clinical Endocrinologists Sixteenth Annual Meeting and Clinical Congress. Seattle, WA, USA, April 11-15, 2007.
Miller PD, McClung MR, Macovei L, et al. 2005. Monthly oral ibandronate therapy in postmenopausal osteoporosis: 1-year results from the MOBILE study. J Bone Miner Res, 20:1315-22.

Monkkonen H, Ottewell PD, Kuokkanen J, et al. 2007. Zoledronic acidinduced IPP/ApppI production in vivo. Life Sci, 81:1066-70.

National Osteoporosis Foundation. 2008. Clinician's Guide to Prevention and Treatment of Osteoporosis [online]. Accessed March 3, 2008. URL: http://www.nof.org/professionals/NOF_Clinicians_Guide.pdf.

Papapoulos SE, Schimmer RC. 2007. Changes in bone remodelling and antifracture efficacy of intermittent bisphosphonate therapy: implications from clinical studies with ibandronate. Ann Rheum Dis, 66:853-8.

Pazianas M, Miller P, Blumentals WA, et al. 2007. A review of the literature on osteonecrosis of the jaw in patients with osteoporosis treated with oral bisphosphonates: prevalence, risk factors, and clinical characteristics. Clin Ther, 29:1548-58.

Perry CM, Figgitt DP. 2004. Zoledronic acid: a review of its use in patients with advanced cancer. Drugs, 64:1197-211.

Poole KE, Kaptoge S, Reeve J. 2007. Yearly zoledronic acid in postmenopausal osteoporosis [letter]. $N$ Engl J Med, 357:711-2; author reply 714-5.

Recker R, Stakkestad JA, Chesnut CH 3rd, et al. 2004. Insufficiently dosed intravenous ibandronate injections are associated with suboptimal antifracture efficacy in postmenopausal osteoporosis. Bone, 34:890-9.

Reginster J, Minne HW, Sorensen OH, et al. 2000. Randomized trial of the effects of risedronate on vertebral fractures in women with established postmenopausal osteoporosis. Vertebral Efficacy with Risedronate Therapy (VERT) Study Group. Osteoporos Int, 11:83-91.

Reginster JY, Adami S, Lakatos P, et al. 2006. Efficacy and tolerability of once-monthly oral ibandronate in postmenopausal osteoporosis: 2 year results from the MOBILE study. Ann Rheum Dis, 65:654-61.

Rizzoli R, Reid DM. 2007. Ibandronate: An IV injection for the treatment for postmenopausal osteoporosis. Bone, 41(5 Suppl 1):S24-8.

Rogers MJ, Gordon S, Benford HL, et al. 2000. Cellular and molecular mechanisms of action of bisphosphonates. Cancer, 88:2961-78.

Rousculp MD, Long SR, Wang S, et al. 2007. Economic burden of osteoporosis-related fractures in Medicaid. Value Health, 10:144-52.

Russell RG, Watts NB, Ebetino FH, et al. 2008. Mechanisms of action of bisphosphonates: similarities and differences and their potential influence on clinical efficacy. Osteoporos Int, Electronically published ahead of print Jan. 24, 2008

Saag K, Lindsay R, Kriegman A, et al. 2007. A single zoledronic acid infusion reduces bone resorption markers more rapidly than weekly oral alendronate in postmenopausal women with low bone mineral density. Bone, 40:1238-43.

Schnitzer T, Bone HG, Crepaldi G, et al. 2000. Therapeutic equivalence of alendronate $70 \mathrm{mg}$ once-weekly and alendronate $10 \mathrm{mg}$ daily in the treatment of osteoporosis. Alendronate Once-Weekly Study Group. Aging (Milano), 12:1-12.

Sebba AI, Bonnick SL, Kagan R, et al. 2004. Response to therapy with once-weekly alendronate $70 \mathrm{mg}$ compared to once-weekly risedronate $35 \mathrm{mg}$ in the treatment of postmenopausal osteoporosis. Curr Med Res Opin, 20:2031-41.

Silverman SL, Barrett-Connor E, Simonelli C, et al. 2007a. Oral monthly ibandronate is associated with rapid suppression of serum CTX within three days of treatment initiation. [abstract W367]. J Bone Miner Res, 22 (Suppl 1):S455.

Silverman SL, Cramer JA, Sunyecz JA, et al. 2007b. Women are more persistent with monthly bisphosphonate therapy compared to weekly bisphosphonates: 12-month results from two retrospective databases [abstract W366]. J Bone Miner Res, 22 (Suppl 1):S454.

Standing Committee on the Scientific Evaluation of Dietary Reference Intakes FaNB, Institute of Medicine. 1997. Dietary Reference Intakes for Calcium, Phosphorus, Magnesium, Vitamin D and Fluoride. Washington, DC: National Academies Press.

Strampel W, Emkey R, Civitelli R. 2007. Safety considerations with bisphosphonates for the treatment of osteoporosis. Drug Saf, 30:755-63.

Sunyecz JA, Weisman SM. 2005. The role of calcium in osteoporosis drug therapy. J Womens Health (Larchmt), 14:180-92. 
US Department of Health and Human Services. 2004. Bone health and osteoporosis: a report of the Surgeon General. Rockville, MD: US Department of Health and Human Services, Office of the Surgeon General.

Weiss TW, Henderson SC, McHorney CA, et al. 2007. Persistence across weekly and monthly bisphosphonates: analysis of US retail pharmacy prescription refills. Curr Med Res Opin, 23:2193-203.
World Health Organization. 1994. Assessment of fracture risk and its application to screening for postmenopausal osteoporosis. Report of a WHO Study Group. World Health Organ Tech Rep Ser, 843:1-129.

Zaidi M, Epstein S, Harris ST, et al. 2007. Progression of efficacy with ibandronate: a paradigm for the development of new bisphosphonates. Ann N Y Acad Sci, 1117:273-82. 
